\title{
The fatty acid profile of subcutaneous and abdominal fat in dairy cows with left displacement of the abomasum
}

\author{
M. Hostens, ${ }^{\star 1}$ V. Fievez,† J. L. M. R. Leroy, $\neq$ J. Van Ranst, † B. Vlaeminck, † and G. Opsomer* \\ *Department of Reproduction, Obstetrics and Herd Health, Faculty of Veterinary Medicine, Ghent University, Salisburylaan 133, \\ 9820 Merelbeke, Belgium \\ †Laboratory for Animal Nutrition and Animal Product Quality, Faculty of Bioscience Engineering, Ghent University, Proefhoevestraat 10 , \\ 9090 Melle, Belgium \\ łLaboratory for Veterinary Physiology and Biochemistry, Department of Veterinary Sciences, Faculty of Biomedical, \\ Pharmaceutical and Veterinary Sciences, University of Antwerp, Universiteitsplein 1, 2610 Wilrijk, Belgium
}

\section{ABSTRACT}

The objective of this study was to determine the fatty acid (FA) profile and assess desaturase indices of nonesterified fatty acids (NEFA) in the blood, as well as in the abdominal (ABD) and subcutaneous (SUBC) fat stores, in dairy cows with left displacement of the abomasum (LDA). Blood, ABD, and SUBC samples were taken from 50 Holstein cows offered for surgery to correct LDA. The FA profile of the 3 compartments was determined by gas chromatography after lipid extraction, methylation, and, in the case of blood plasma, separation of lipid classes. The most abundant FA in all 3 compartments were 16:0, 18:0, and 18:1 cis-9, with a total proportion of $82.5,68.0$, and $74.1 \mathrm{~g} / 100 \mathrm{~g}$ of FA in $\mathrm{ABD}, \mathrm{NEFA}$, and SUBC, respectively. A principal component analysis was performed on the entire FA profile as well as on the $\Delta^{9}$-desaturase indices (14:1 cis-9/14:0, 16:1 cis-9/16:0, 18:1 cis-9/18:0). The principal component analysis extracted 2 principal components (PC), representing $51.6 \%(\mathrm{PC} 1)$ and $21.1 \%(\mathrm{PC} 2)$ of the total variance in FA composition of the 3 compartments. The loading plot for the regression factors revealed a strong positive correlation between $\mathrm{PC} 1$ with the $\Delta^{9}$-desaturase indices and the proportions of 14:1 cis-9 and 16:1 cis-9, and revealed a negative correlation with the proportion of 18:0 and saturated FA. The correlation with PC2 was positive for the proportion of unsaturated FA, 18:2n-6, and 18:3n-3, and negative for the proportion of 14:0, 16:0, and saturated FA. The SUBC could be distinguished from the NEFA and ABD by a positive score for PC1, whereas differentiation among the latter 2 compartments could be made by a positive (NEFA) or negative $(\mathrm{ABD})$ score for $\mathrm{PC} 2$. The $\Delta^{9}$-desaturase indices for C14 and C16 differed between all compartments but were numerically closer for NEFA and ABD

Received October 26, 2011.

Accepted March 8, 2012.

${ }^{1}$ Corresponding author: Miel.Hostens@UGent.be versus NEFA and SUBC. The desaturase indices of the main FA (18:1 cis-9 and 18:0) did not differ between NEFA and ABD. These results support the existence of a different FA composition in ABD compared with SUBC. The greater similarity between the FA profiles of ABD and NEFA compared with SUBC and NEFA and the closer desaturase indices of ABD and NEFA support the hypothesis of a preferential mobilization of ABD fat in dairy cows with LDA.

Key words: cow, abdominal fat, subcutaneous fat, nonesterified fatty acids

\section{INTRODUCTION}

The onset of lactation in dairy cows is typically characterized by several vast metabolic adaptations. An imbalanced energy input-output switches the metabolism of the dairy cow from an anabolic to a catabolic state, commonly called the negative energy balance (NEBAL). Homeorhetic control mechanisms ensure that body reserves, mainly the adipose tissues, will be mobilized to meet this temporary energy deficit (Bauman and Currie, 1980). This body fat mobilization results in an increase in blood NEFA concentrations around parturition. Elevated NEFA concentrations impair metabolic and immune cell function in humans (Mora and Pessin, 2002) and are associated with impaired metabolic health in transition cows (Herdt, 2000; Jorritsma et al., 2003; Bobe et al., 2004). In particular, the saturated NEFA have been associated with direct toxic effects for bovine oocytes, embryos, and granulosa cells, being an important metabolic link between metabolic pressure and subfertility in dairy cows (Leroy et al., 2005; Vanholder et al., 2005; Van Hoeck et al., 2011). The chain length, degree of saturation, and position of the double bonds in FA determine their function in different biological processes (Mattos et al., 2000). Immune cell function has been shown to be impaired by saturated NEFA in humans (Håversen et al., 2009) and periparturient dairy cows (Contreras 
and Sordillo, 2011), whereas positive health effects have been attributed to unsaturated FA in both humans (Calder, 2009) and dairy cows (Aardema et al., 2011). Moreover, lipomobilization in early lactation releases large amounts of FA (up to $3.2 \mathrm{~kg} / \mathrm{d}$; Drackley et al., 2001) mainly from the subcutaneously (SUBC) and abdominally (ABD) stored fat depots. The SUBC fat is known to have a more unsaturated FA profile than $\mathrm{ABD}$, as the level of saturation increases with increasing distance from the animal's exterior (De Smet et al., 2004). In humans, omental and mesenteric adipocytes are more metabolically active and sensitive to lipolysis than SUBC adipocytes (Wajchenberg, 2000; Jensen, 2007; Hajer et al., 2008). In Holstein-Friesian heifers, ABD adipocytes have been shown to possess, when not adjusted for their larger cell size, a greater lipogenic enzyme activity per cell compared with SUBC adipocytes (Eguinoa et al., 2003). We hypothesized that ABD and SUBC fat tissues have different FA profiles, rendering them at a different level of pathogenicity in case of lipolysis. Therefore, the objective of this study was to determine the FA profile of the plasma NEFA fraction and the ABD and SUBC fat depots in dairy cows during an episode of severe NEBAL in the postpartum period.

\section{MATERIALS AND METHODS}

\section{Cows and Experimental Design}

Between July 2008 and January 2009, 7 veterinarians took samples from dairy cows offered for surgery to correct a left displacement of the abomasum (LDA). The average monthly temperature as registered by the Royal Meteorological Institute of Belgium (Ukkel, Belgium) in this period was $8.7^{\circ} \mathrm{C}$, with a range from 0.7 to $17.6^{\circ} \mathrm{C}$. An average monthly relative humidity of $84 \%$ was reported, with a range from 75 to $91 \%$. Cow-specific data (breed, calving date, parity) were collected at the time of surgery. At the same moment, each veterinarian recorded the BCS on a 1 to 5 scale, with 0.25 increments (Edmonson et al., 1989), together with the omental fat score (OFS) based on a 5-point scale as described by Van Eetvelde et al. (2011). In total, samples were collected from 50 cows that were black and white (83\%) and red and white Holsteins $(17 \%)$. The contribution of first-parity and older cows was $39 \%$ and $61 \%$, respectively. The median DIM at the time of sampling (day of LDA surgery) was 11 (range: 1-113 DIM). No individual feed intakes were available as samples were taken from cows on commercial dairy herds. Typical for the part of Belgium where samples were taken, postpartum rations were based on corn and grass silage supplemented with sugar beet pulp, in addition to concentrate and a protein supplement.

\section{Sampling}

Prior to surgery, blood samples were taken from the coccygeal vein into a tube with EDTA as anticoagulant (Venoject, Autosep, Terumo Europe, Leuven, Belgium). Blood samples were taken before surgery to avoid elevated NEFA concentrations due to stress (Leroy et al., 2011). Within $2 \mathrm{~h}$ after collection, blood samples were centrifuged $(1,500 \times g, 20 \mathrm{~min})$, and the plasma was stored at $-20^{\circ} \mathrm{C}$ until analysis. The animals were prepared for left paralumbar fossa abomasopexy or right paralumbar fossa omentopexy as described by Turner et al. (1989). After incision of the skin, a subcutaneous fat sample $(1 \mathrm{~g})$ was harvested. After removal of most of the blood with blotting paper, the sample was deposited into a 10-mL tube containing PBS to remove the rest of the blood. After the peritoneal cavity was opened, omental fat (1 g) was dissected. The latter fat sample was treated similarly as the subcutaneous sample. The fat samples were subsequently placed into tubes without PBS and stored at $-20^{\circ} \mathrm{C}$ until further analysis.

\section{Chemical Analysis}

The blood plasma analysis for aspartate aminotransferase, BHBA, $\gamma$-glutamyltransferase, and NEFA was carried out by means of an automated colorimetrical analyzer (Konelab 20 XTi clinical chemistry analyzer, Thermo Electron Corp., Vantaa, Finland) at The Flemish Veterinary Health Service (DierengezondheidszorgVlaanderen, Torhout, Belgium).

\section{Lipid Extraction}

Lipids in abdominal and subcutaneous fat were extracted with 2:1 chloroform:methanol ( $\mathrm{vol} / \mathrm{vol}$ ) as described by Lourenço et al. (2007). Lipids in blood plasma $(0.5 \mathrm{~mL})$ were extracted overnight with $2: 1$ chloroform:methanol $(10 \mathrm{~mL}, \mathrm{vol} / \mathrm{vol})$ and butylated hydroxytoluene in chloroform $(0.5 \mathrm{~mL}, 0.1 \% \mathrm{wt} / \mathrm{vol})$ as described by Raes et al. (2001). Samples were filtered (Fiorini Filtres, Ingré, France) and the filtrate collected in extraction tubes containing $15 \mathrm{~mL}$ of distilled water. The original tubes (2 times) and filter were washed with $5 \mathrm{~mL}$ of 2:1 chloroform:methanol ( $\mathrm{vol} / \mathrm{vol})$. After shaking and centrifugation $(1,821 \times g, 10 \mathrm{~min})$, the aqueous layer was removed. The remaining liquid in the extraction tube was further allowed to separate in a separatory funnel. The extracts were evaporated in a water bath at 
$40^{\circ} \mathrm{C}$ using a rotary evaporator and subsequently dissolved in $10 \mathrm{~mL}$ of 2:1 chloroform:methanol ( $\mathrm{vol} / \mathrm{vol}$ ). Extracts were stored at $-20^{\circ} \mathrm{C}$. Lipids in plasma were fractionated in neutral (triacylglycerol and cholesteryl esters), NEFA, and phospholipids using an aminopropyl silica column (Bond Elut-NH2, Varian Medical Systems Belgium, Diegem, Belgium). After washing the column with hexane $(2 \times 1 \mathrm{~mL})$, lipids were loaded in $1 \mathrm{~mL}$ of chloroform containing an internal standard (17:0). Neutral lipids were eluted with chloroform $(6 \times 0.5$ $\mathrm{mL}$ ). The NEFA fraction was eluted with $2 \%$ acetic acid in diethyl ether $(6 \times 0.5 \mathrm{~mL})$. Finally, the polar fraction was eluted with $6: 1$ chloroform:methanol (vol/ vol, $3 \times 0.5 \mathrm{~mL})$ followed by sodium acetate $(0.05 M)$ in $6: 1$ chloroform:methanol (vol/vol, $3 \times 0.5 \mathrm{~mL}$ ).

\section{Methylation and GC Analysis}

Fatty acids in lipid extracts and lipid fractions were methylated with $\mathrm{NaOH} / \mathrm{MeOH}(0.5 M)$ followed by $\mathrm{HCl} / \mathrm{MeOH}(1: 1 ; \mathrm{vol} / \mathrm{vol})$ as described by Raes et al. (2001). After extraction of the fatty acid methyl esters (FAME) with hexane and evaporation under a stream of nitrogen, the FAME were finally dissolved in hexane, $1 \mathrm{~mL}$ for abdominal and subcutaneous fat and $250 \mu \mathrm{L}$ for the NEFA fraction in plasma lipids, respectively. The FAME were stored at $-18^{\circ} \mathrm{C}$ until further analysis.

The FAME analysis was performed with a gas chromatograph (Hewlett-Packard 6890 gas chromatograph, Hewlett-Packard, Brussels, Belgium) equipped with a SolGel-wax column $(30 \mathrm{~m} \times 0.25 \mathrm{~mm} \times 0.25 \mu \mathrm{m}$; SGE Analytical Science, Victoria, Australia). The temperature program was $150^{\circ} \mathrm{C}$ for $2 \mathrm{~min}$, increasing at $3^{\circ} \mathrm{C} /$ min until $250^{\circ} \mathrm{C}$. The injection temperature was set at $250^{\circ} \mathrm{C}$, and the detector temperature was fixed at $280^{\circ} \mathrm{C}$.

\section{Data Handling and Statistical Analysis}

All statistical analyses were performed using SAS software (release 9.2, SAS Institute Inc., Cary, NC). Descriptive statistics (mean, SD, median, and range) were done using the MEANS procedure. The Pearson correlation was calculated between BCS and OFS with the CORR procedure after standardization by subtracting the mean average veterinarian BCS and OFS to account for the effect of the different veterinarians that participated in the study. Fatty acids were grouped according to the degree of saturation in SFA (14:0, 16:0, 18:0), MUFA (14:1 cis-9, 16:1 cis-9, 18:1 cis-9, 18:1 trans-11), and PUFA (18:2 cis-9,trans-11, 18:2n-6, 18:3n-3). The $\Delta^{9}$-desaturase indices were calculated as the ratio between the product and its precur- sor for 14:1 cis-9/14:0 (C14 ratio), 16:1 cis-9/16:0 (C16 ratio), and 18:1 cis-9/18:0 (C18 ratio). The MIXED procedure was used to analyze the effect of the compartment (plasma NEFA, ABD, and SUBC) on FA composition. The model included compartment and cow as fixed and random effects, respectively. Data are reported as model least squares means with standard errors unless indicated otherwise. Significance and tendency were declared at $P<0.05$ and $0.05<P<0.1$ respectively. A principal components analysis (PCA) using the PRINCOMP procedure was conducted after standardization of the data. The objective of the PCA is to synthesize the overall information in a large set of variables into a smaller number of linear combinations of orthogonal variables called principal components (PC). The analysis sequentially minimizes the remaining variation in the multivariate data. As a result, the PCA condenses the information into loadings that show the relative importance of the original variables in accounting for the variability in the observed data, which is shown in a loading plot. Finally, the distribution of the observed data across the PC is shown by the scores in a score plot (Desnoyers et al., 2011). Each object (cow $\times$ compartment) was analyzed to be a data vector of 16 variables (14:0, 14:1 cis-9, 16:0, 16:1 cis-9, 18:0, 18:1 cis-9, 18:1 trans-11, 18:2 cis-9,trans-11, 18:2n-6, 18:3n-3, SFA, MUFA, PUFA, C14 ratio, C16 ratio, C18 ratio). Compartment effects were evaluated for the individual PC scores for PC1 and PC2 with the same MIXED procedure as reported for the individual FA.

\section{RESULTS}

\section{Chemical Composition of Blood Plasma}

The descriptive statistics of the blood plasma aspartate aminotransferase, BHBA, $\gamma$-glutamyltransferase, and NEFA concentration are represented in Table 1. The NEFA concentration in blood plasma averaged 1.28 $\pm 0.61 \mathrm{mmol} / \mathrm{L}($ mean $\pm \mathrm{SD}$ ) with a range from 0.21 to $2.93 \mathrm{mmol} / \mathrm{L}$. The BHBA concentration in blood plasma was $2.48 \pm 1.94 \mathrm{mmol} / \mathrm{L}$ (mean $\pm \mathrm{SD}$ ) with a range from 0.34 to $8.40 \mathrm{mmol} / \mathrm{L}$.

Table 1. Blood plasma metabolite concentrations in dairy cows suffering from a left displacement of the abomasum

\begin{tabular}{lccc}
\hline Item $^{1}$ & Mean \pm SD & Median & Range \\
\hline NEFA, mmol/L & $1.28 \pm 0.61$ & 1.16 & $0.21-2.93$ \\
BHBA, mmol/L & $2.48 \pm 1.94$ & 2.01 & $0.34-8.40$ \\
GGT, IU/L & $205 \pm 92$ & 187 & $66-557$ \\
AST, IU/L & $39 \pm 46$ & 30 & $6-295$ \\
\hline
\end{tabular}

${ }^{1}$ GGT $=\gamma$-glutamyltransferase; AST $=$ aspartate aminotransferase. 


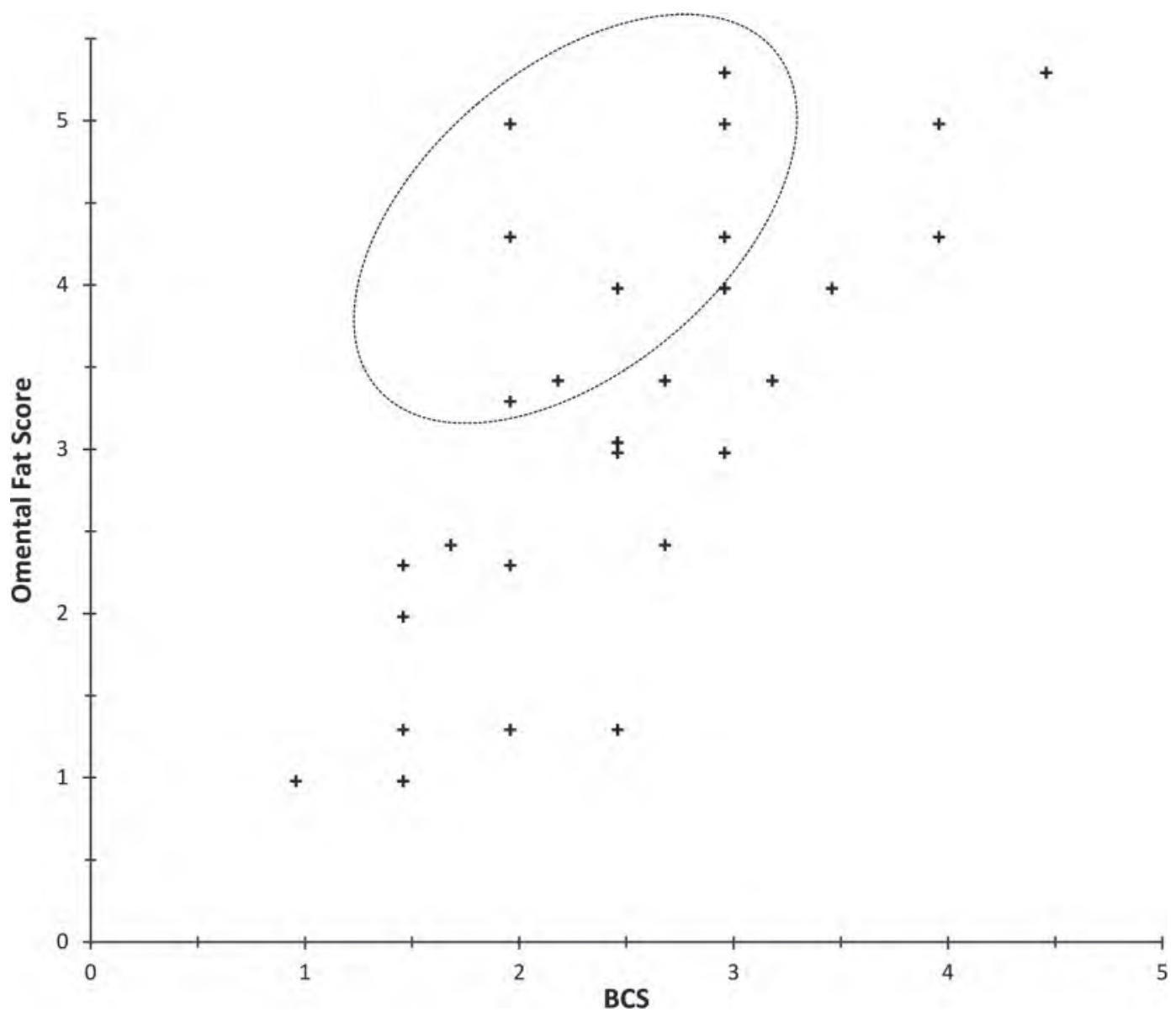

Figure 1. Scatterplot presenting the correlation between BCS and omental fat score at the moment of correction for a left abomasal displacement. The oval includes cows with a high omental fat score and normal BCS $(\mathrm{n}=46)$.

\section{Correlation Between BCS and OFS}

Four cows had missing data for BCS and OFS and were not included in the correlation analysis. The mean standardized BCS and OFS were $2.46 \pm 1.18$ and 2.46 \pm 0.70 , respectively. A positive Pearson correlation coefficient of 0.73 was calculated between both scores $(P$ $<0.0001$ ) and is represented in Figure 1. Nevertheless, some observations had a high OFS and normal BCS, indicated by the oval in Figure 1.

\section{FA Composition of Plasma NEFA, ABD Fat, and SUBC Fat}

Least squares means of the FA proportion by weight of total identified FA in ABD, NEFA, and SUBC in dairy cows are shown in Table 2 and Figure 2. The 3 most abundant FA in all compartments, 16:0, 18:0, and $18: 1$ cis-9, represented $82.5,68.0$, and $74.1 \%$ of the total FA in ABD, NEFA and SUBC, respectively. The highest level of saturation (SFA) was found in ABD fol- lowed by NEFA and SUBC $(P<0.0001)$. The proportion of MUFA was significantly higher in SUBC than in ABD and NEFA $(P<0.0001)$. The PUFA level was higher in NEFA compared with ABD and SUBC $(P<$ $0.0001)$. The $\Delta^{9}$-desaturase indices for $\mathrm{C} 14$ and $\mathrm{C} 16$ were lowest in ABD and highest in SUBC $(P<0.0001)$. The C18-ratio was lower in ABD and NEFA compared with SUBC $(P<0.0001$; Figure 3$)$. The PCA extracted $16 \mathrm{PC}$, of which the first 2 represented $51.6 \%$ (PC1) and $21.1 \%$ ( $\mathrm{PC} 2$ ) of the total variance in $\mathrm{FA}$ composition and desaturase indices in the 3 compartments. The loading plot for the regression factors (Figure 4) revealed a strong positive correlation between $\mathrm{PC} 1$ with the $\Delta^{9}$-desaturase indices and with the proportion in fat of $16: 1$ cis-9 and 14:1 cis-9, and a negative correlation with the proportions of 18:0 and SFA. The correlation with $\mathrm{PC} 2$ was positive for the proportion of PUFA, 18:2n-6, and 18:3n-3, and was negative for the proportion of 14:0, 16:0, and SFA. The PCA score plot (Figure 5) shows a differentiation between the 3 compartments based on both PC1 and PC2. The SUBC 
Table 2. Fatty acid composition ( $\mathrm{g} / 100 \mathrm{~g}$ of FA) of the 3 main fat compartments in dairy cows suffering from a left displacement of the abomasum ${ }^{1}$

\begin{tabular}{|c|c|c|c|c|c|}
\hline \multirow[b]{2}{*}{ Item } & \multicolumn{3}{|c|}{ Compartment } & \multirow[b]{2}{*}{ SEM } & \multirow[b]{2}{*}{$P$-value } \\
\hline & Abdominal & NEFA & Subcutaneous & & \\
\hline \multicolumn{6}{|l|}{ Fatty acid } \\
\hline $14: 0$ & $2.52^{\mathrm{a}}$ & $1.80^{\mathrm{b}}$ & $3.03^{\mathrm{c}}$ & 0.098 & $<0.0001$ \\
\hline $14: 1$ cis -9 & $0.22^{\mathrm{a}}$ & $0.30^{\mathrm{a}}$ & $1.57^{\mathrm{b}}$ & 0.090 & $<0.0001$ \\
\hline $16: 0$ & $24.7^{\mathrm{a}}$ & $22.0^{\mathrm{b}}$ & $25.2^{\mathrm{a}}$ & 0.48 & $<0.0001$ \\
\hline $16: 1$ cis -9 & $1.30^{\mathrm{a}}$ & $2.02^{\mathrm{a}}$ & $6.07^{\mathrm{b}}$ & 0.255 & $<0.0001$ \\
\hline $18: 0$ & $26.6^{\mathrm{a}}$ & $20.1^{\mathrm{b}}$ & $11.0^{\mathrm{c}}$ & 0.61 & $<0.0001$ \\
\hline $18: 1$ cis -9 & $31.1^{\mathrm{a}}$ & $26.2^{\mathrm{b}}$ & $37.9^{\mathrm{c}}$ & 0.79 & $<0.0001$ \\
\hline $18: 1$ trans -11 & $1.97^{\mathrm{a}}$ & $2.14^{\mathrm{ab}}$ & $2.31^{\mathrm{b}}$ & 0.100 & $<0.0001$ \\
\hline $18: 2$ cis- 9, trans -11 & $0.272^{\mathrm{a}}$ & $0.288^{\mathrm{a}}$ & $0.644^{\mathrm{b}}$ & 0.0459 & $<0.0001$ \\
\hline $18: 2 \mathrm{n}-6$ & $0.94^{\mathrm{a}}$ & $3.02^{\mathrm{b}}$ & $0.87^{\mathrm{a}}$ & 0.107 & $<0.0001$ \\
\hline $18: 3 n-3$ & $0.31^{\mathrm{a}}$ & $0.72^{\mathrm{b}}$ & $0.27^{\mathrm{a}}$ & 0.022 & $<0.0001$ \\
\hline \multicolumn{6}{|l|}{ Summation $^{2}$} \\
\hline SFA & $53.9^{\mathrm{a}}$ & $44.0^{\mathrm{b}}$ & $39.3^{\mathrm{c}}$ & 0.84 & $<0.0001$ \\
\hline MUFA & $34.6^{\mathrm{a}}$ & $30.7^{\mathrm{b}}$ & $47.9^{\mathrm{c}}$ & 0.97 & $<0.0001$ \\
\hline PUFA & $1.52^{\mathrm{a}}$ & $4.02^{\mathrm{b}}$ & $1.79^{\mathrm{a}}$ & 0.117 & $<0.0001$ \\
\hline \multicolumn{6}{|l|}{$\Delta^{9}$-Desaturase index ${ }^{3}$} \\
\hline C14-ratio & $0.088^{\mathrm{a}}$ & $0.167^{\mathrm{b}}$ & $0.505^{\mathrm{c}}$ & 0.0274 & $<0.0001$ \\
\hline C16-ratio & $0.054^{\mathrm{a}}$ & $0.091^{\mathrm{b}}$ & $0.242^{\mathrm{c}}$ & 0.0107 & $<0.0001$ \\
\hline C18-ratio & $1.22^{\mathrm{a}}$ & $1.37^{\mathrm{a}}$ & $4.17^{\mathrm{b}}$ & 0.172 & $<0.0001$ \\
\hline Total FA content & 56.9 & & 48.4 & 2.99 & 0.006 \\
\hline
\end{tabular}

${ }^{\mathrm{a}-\mathrm{C}}$ Values with different subscripts in the same row significantly differ $(P<0.05)$.

${ }^{1}$ Values are model least squares means.

${ }^{2} \mathrm{SFA}=14: 0+16: 0+18: 0 ;$ MUFA $=14: 1$ cis $-9+16: 1$ cis-9 $+18: 1$ cis-9 $+18: 1$ trans-11; PUFA $=18: 2$ cis-9, trans-11 + 18:2 n- $6+18: 3 \mathrm{n}-3$.

${ }^{3} \mathrm{C} 14$-ratio $=14: 1$ cis-9/14:0; C16-ratio $=16: 1$ cis-9/16:0; C18-ratio = 18:1 cis-9/18:0.

could be distinguished from the NEFA and ABD by a positive score for $\mathrm{PC} 1$. The differentiation between the 2 compartments with a negative score for PC1 could be made by a positive (NEFA) or negative (ABD) score for $\mathrm{PC} 2$, which is illustrated by the mean $\mathrm{PC} 1$ scores for SUBC that differ from those of ABD and NEFA $(P$ $<0.0001)$. The individual PC2 scores differed between all classes $(P<0.0001$; Table 3$)$.

\section{DISCUSSION}

Many studies have focused on the deleterious effects of lipolysis in dairy cattle. To our knowledge, the current study is the first to investigate the FA profile of plasma NEFA, and ABD and SUBC fat stores in dairy cows during NEBAL. First, the metabolic blood profile from the animals in this experiment, especially the high NEFA and high BHBA support the working hypothesis of sampling animals in severe NEBAL when suffering from LDA (LeBlanc et al., 2005; Chapinal et al., 2011).

We hypothesized that ABD and SUBC fat tissues would have different FA profiles rendering them at a different level of pathogenicity in case of lipolysis, as it is known that lipotoxicity of FA increases with their level of saturation (Leroy et al., 2005; Vanholder et al., 2005; Van Hoeck et al., 2011). As the data are limited in this research area, we compared our results for the individual FA (Figure 2) and the $\Delta^{9}$-desaturase indices (Figure 3) with data from both dairy and beef cattle. In general, the SUBC FA profile was in agreement with those reported in dairy (Rukkwamsuk et al., 2000; Sato and Inoue, 2006; Douglas et al., 2007; Zachut et al., 2010a) and in beef cattle (Eichhorn et al., 1986; Beaulieu et al., 2002; Oka et al., 2002; Siebert et al., 2003). Omental FA profiles are seldom reported in both dairy (Sato and Inoue, 2006) and beef cattle (Beaulieu et al., 2002) but seem consistent with perirenal FA profiles (dairy: Sato and Inoue, 2006; beef: Eichhorn et al., 1986; Beaulieu et al., 2002; Oka et al., 2002). In our study, the FA with the highest contribution to the ABD and SUBC FA was 18:1 cis-9, which is in agreement with previous dairy (Rukkwamsuk et al., 2000; Sato and Inoue, 2006; Douglas et al., 2007; Zachut et al., 2010a) and beef cattle studies (Eichhorn et al., 1986; Beaulieu et al., 2002; Oka et al., 2002; Siebert et al., 2003), although the concentrations mentioned in previous studies were higher (Figure 2). In the present study, palmitic acid (16:0) represented the second largest proportion of the SUBC FA, followed by stearic acid (18:0), which is in agreement with all aforementioned beef and dairy cattle studies. The higher contribution of 18:0 compared with 16:0 in ABD was not found in all dairy (Sato and Inoue, 2006) and beef cattle studies (Beaulieu et al., 2002; Oka et al., 2002). 


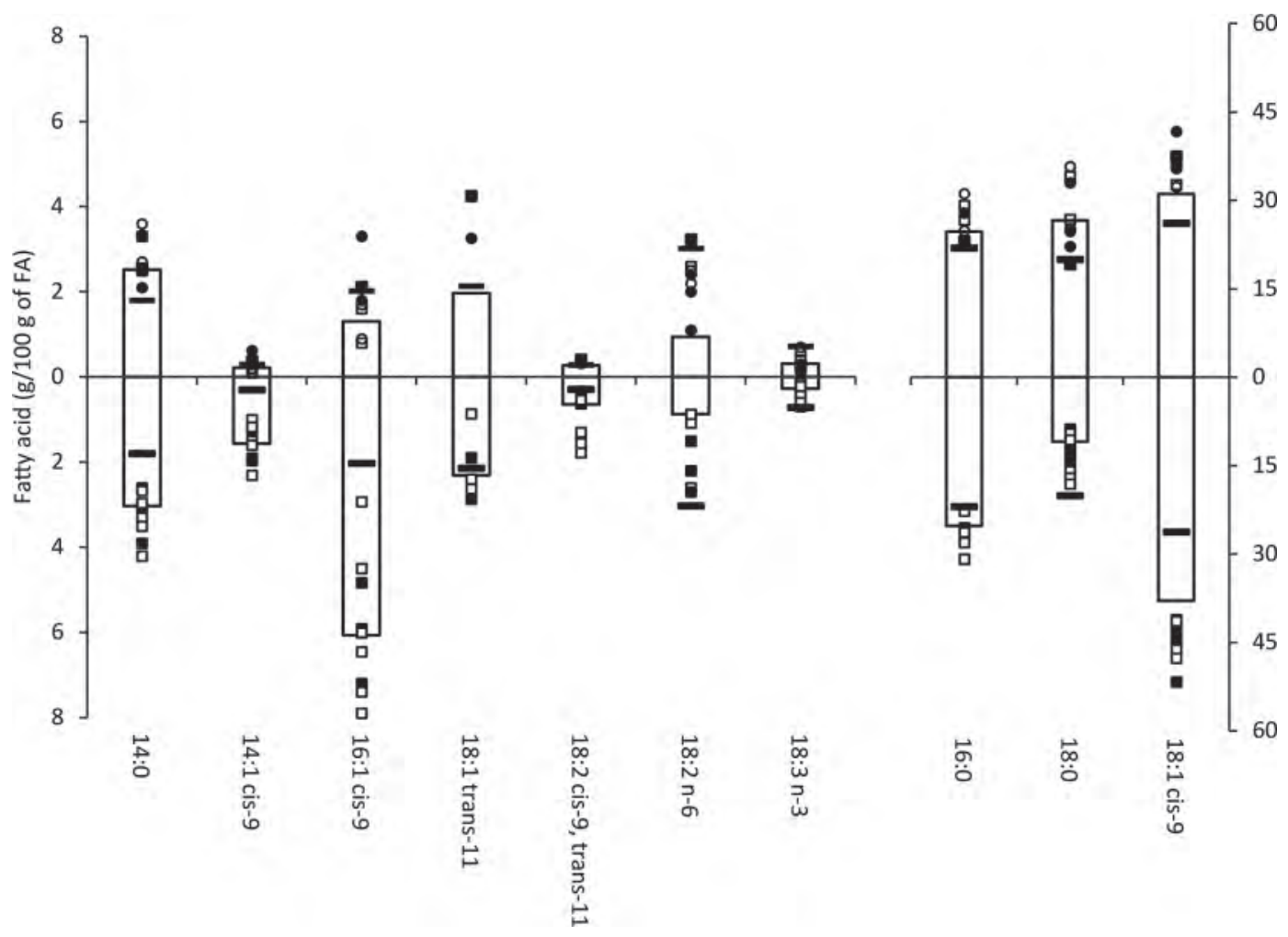

Figure 2. Bar chart combining the individual fatty acid composition of abdominal fat (above the horizontal axis), subcutaneous fat (below the horizontal axis), and NEFA (-) in dairy cows suffering from a left displacement of the abomasum. The cited literature is indicated for dairy (open symbols: Rukkwamsuk et al., 2000; Sato and Inoue, 2006; Douglas et al., 2007; Zachut et al., 2010a) or beef (black symbols: Eichhorn et al., 1986; Beaulieu et al., 2002; Oka et al., 2002; Siebert et al., 2003) cattle. The abdominal depot is presented as mesenteric (squares) or perirenal (circles) fat. To allow better comparison with both adipose tissues, blood plasma NEFA proportions as measured in the current study were presented both in the upward and downward bars.

Furthermore, we aimed to find out which of the 2 fat stores is preferentially broken down in lactating dairy cows with LDA. The latter was done by comparing the FA profile of these 2 fat stores with the profile of NEFA circulating in the peripheral circulation. To enhance the interpretation of the FA profile in circulating NEFA compared with $\mathrm{ABD}$ and SUBC, we included the NEFA composition from the current study in Figures 2 and 3. Until now, dairy cattle experiments that compared the FA composition of different adipose compartments with blood mainly reported the total lipid content of plasma, which includes the dietary FA, making the interpretation of the FA contribution by the different body fat depots to circulating NEFA challenging (Douglas et al., 2007; Zachut et al., 2010a). Three experiments (Moallem et al., 1999; Leroy et al., 2005; Contreras et al., 2010) involving healthy dairy cows showed a major contribution of 16:0, 18:0, and 18:1 cis-9 to the circulating NEFA, as in our study. Compared with our results, Moallem et al. (1999) and Contreras et al. (2010) showed remarkably higher 16:0 and 18:0 and lower 18:1 cis-9 contents. This higher level of SFA in NEFA has been linked to an altered leukocyte function early postpartum, enhancing susceptibility to transition diseases (Contreras and Sordillo, 2011). Therefore, from our study, cows with LDA would be experiencing a less severe proinflammatory environment. However, a greater contribution of 18:1 cis-9 has been observed in healthy dairy cows early postpartum as well (d 16; Leroy et al., 2005). Future research on the composition of NEFA in early lactating dairy cows is therefore needed to further distinguish physiological (stage of lactation, diet, breed) and pathophysiological effects.

Because of the reported differences in FA profile, the ratios of the products and their precursors (14:1 cis-9/14:0, 16:1 cis-9/16:0, and 18:1 cis-9/18:0) were greater in SUBC compared with NEFA and ABD. Similar differences between SUBC and ABD were observed in other dairy (Sato and Inoue, 2006) and beef cattle studies (Beaulieu et al., 2002; Oka et al., 2002). The largest range was found for the SUBC C18 ratio, which ranged from 2.29 (Zachut et al., 2010b) to 5.90 (Oka et al., 2002), followed by the SUBC C14 ratio, which ranged from 0.33 (Sato and Inoue, 2006) to 0.62 (Siebert et al., 2003). The reported ABD C14 and C16 


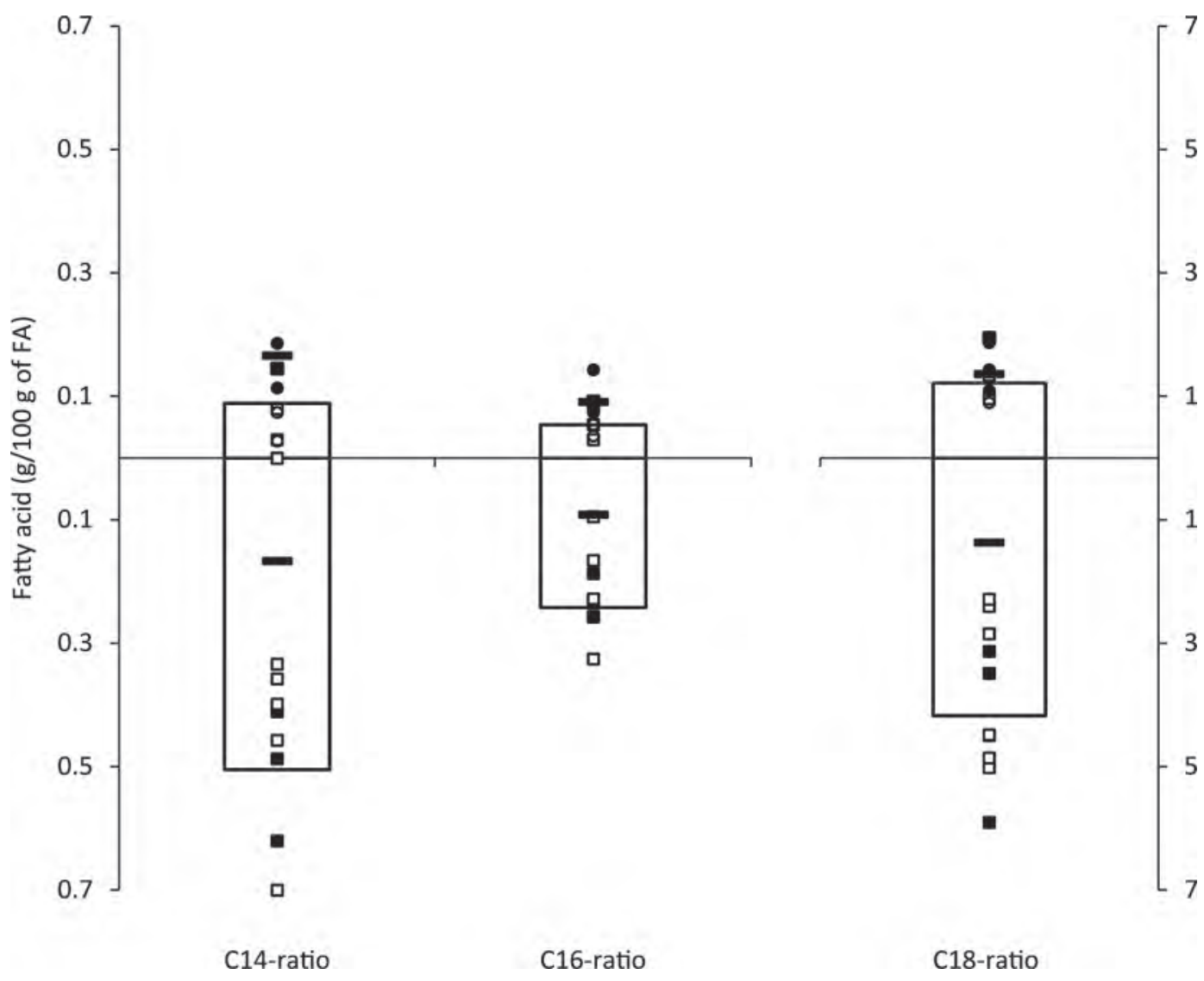

Figure 3. Bar chart combining columns for $\Delta^{9}$-desaturase indices (C14, C16, C18 ratios) of abdominal fat (above the horizontal axis), subcutaneous fat (below the horizontal axis), and NEFA (-) in dairy cows suffering from a left displacement of the abomasum. The cited literature is indicated for dairy (open symbols: Eichhorn et al., 1986; Beaulieu et al., 2002; Oka et al., 2002; Siebert et al., 2003) or beef (black symbols: Eichhorn et al., 1986; Beaulieu et al., 2002; Oka et al., 2002; Siebert et al., 2003) cattle. The abdominal depot is presented as mesenteric (squares) or perirenal (circles) fat. To allow better comparison with both adipose tissues, blood plasma NEFA $\Delta^{9}$-desaturase indices as measured in the current study were presented both in the upward and downward bars.

ratios, but not the $\mathrm{C} 18$ ratio mentioned in beef studies (Eichhorn et al., 1986; Beaulieu et al., 2002; Oka et al., 2002), were generally greater compared with our study and other dairy cattle experiments (Figure 3; Sato and Inoue, 2006). Stearoyl-CoA desaturase (SCD), which is responsible for the conversion of 14:0 to 14:1 cis-9, 16:0 to $16: 1$ cis-9, and 18:0 to 18:1 cis-9, was found in bovine liver (St. John et al., 1991) and subcutaneous fat stores (Chang et al., 1992), but not in the NEFA fraction of plasma, as SCD expression is regulated at the cellular transcriptional level (Nakamura and Nara, 2004). Therefore, the $\Delta^{9}$-desaturase indices did not change in the blood (NEFA) and hence could reflect the main site of lipolysis. The desaturase index of the proportionally main FA (18:1 cis-9 and 18:0) was not different between NEFA and ABD. Moreover, even though they were significantly different, the $\Delta^{9}$-desaturase indices for the $\mathrm{C} 14$ and $\mathrm{C} 16$ ratios in NEFA were closer to those of ABD than to those of SUBC. Finally, loading plots of PCA appear to offer an interesting way to indicate mutual metabolic relationships between milk FA and their origin (Fievez et al., 2003). Therefore, we used a similar approach to find clusters in the FA patterns originating from the different lipid compartments. We were able to show that the ABD and NEFA have a more similar FA profile as suggested by the $\mathrm{PC} 1$ that does not differ between ABD and NEFA compared with SUBC. These findings further strengthen our conclusion that the FA profile of NEFA is closer to that of ABD compared with SUBC.

The significant difference in contribution to the overall lipomobilization between the different fat depots is important in relation to the development of metabolic disorders in dairy cows (Mukesh et al., 2010), as specific FA profiles in circulating NEFA during early lactation have been suggested to potentially affect inflammatory responses in transition dairy cows (Contreras et al., 2010). In ruminants, as in humans (Arner, 1998), the visceral but not the subcutaneous tissue is drained by the portal venous system, thus being in direct contact 


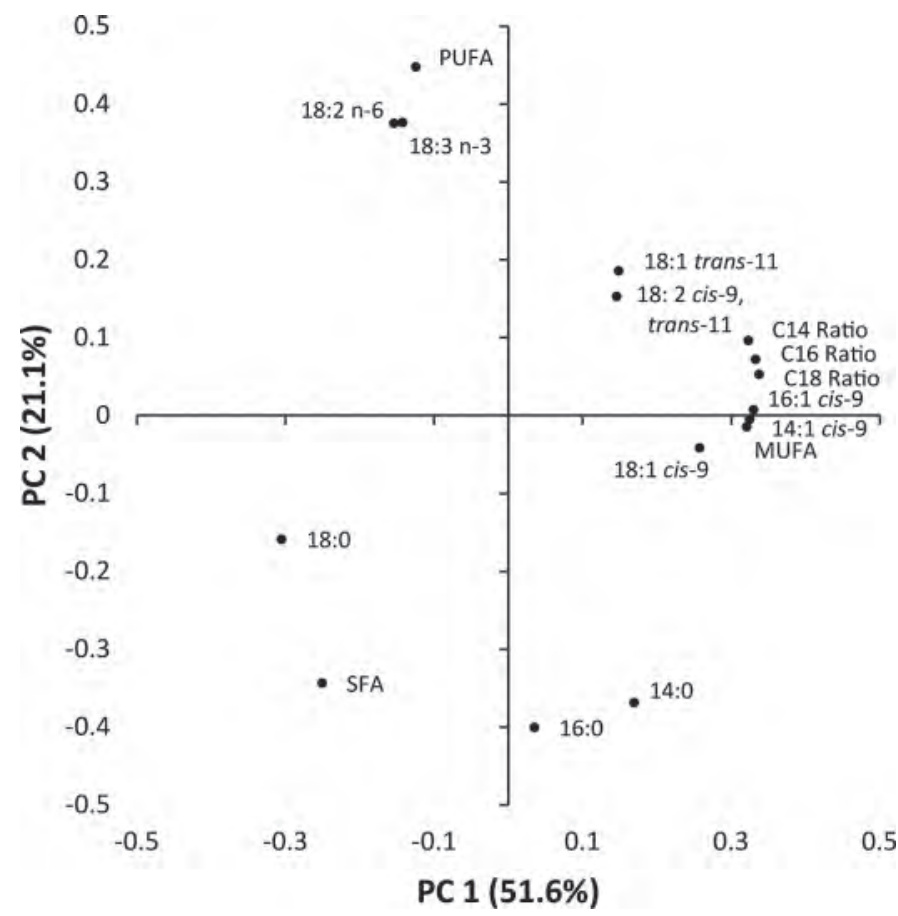

Figure 4. Loading plot presenting the relationship among FA derived from a principal component (PC) analysis based on proportions (\% of total FA) of C14 to C18 FA, proportions of SFA, MUFA, and PUFA, and the $\Delta^{9}$-desaturase indices in the NEFA fraction of plasma and abdominal and subcutaneous fat $(\mathrm{n}=150)$ in dairy cows suffering from a left displacement of the abomasum.

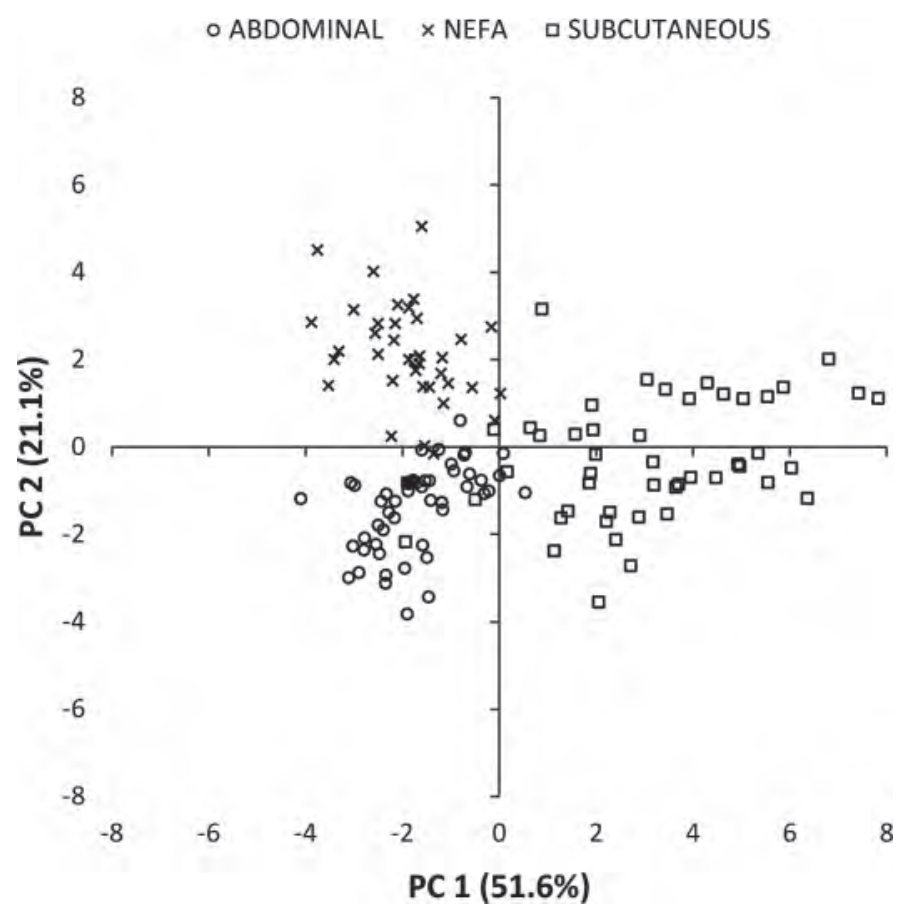

Figure 5. Score plot of the individual samples, from the principal components $(\mathrm{PC})$ analysis in Figure 4, represented according to the compartment of origin: abdominal fat $(O)$, NEFA $(x)$, and subcutaneous fat $(\square)$, in dairy cows suffering from a left displacement of the abomasum. with the liver (Emery et al., 1992). Considering that the latter organ serves as the principal actor in nutrient metabolization during the periparturient period of dairy cows, a temporary overflow by visceral FA may render the animal more susceptible to several kinds of metabolic diseases in the most crucial period of the lactation cycle (Drackley et al., 2001). Two mechanisms might cause the observed differences in FA metabolism in the fat compartments. First, in ruminants, the blood flow to carcass fat depots is lower than that to abdominal fat depots, especially in the immediate postpartum period (Vernon, 1980; Barnes et al., 1983; Gregory et al., 1986), leading to a temporary decreased nutrient flow to and from the SUBC. The second mechanism might be related to site-specific differences in lipogenic and lipolytic rates. Previous reports in beef cattle have reported greater lipolytic (Etherton et al., 1977) and lipogenic (Baldwin et al., 2007) rates in subcutaneous fat compared with perirenal fat. This difference in metabolic activity between the different fat depots had previously been proposed by Eguinoa et al. (2003) as a compensatory mechanism for the decreased nutrient flow in the carcass. The latter authors investigated differences in lipogenic rate between different depots in nonlactating Holstein heifers and concluded that the greater lipogenic rate seen in subcutaneous fat has to be adjusted for adipocyte size, resulting in a higher net 
Table 3. Principal components (PC) for the FA profile of the 3 main fat compartments in dairy cows suffering from a left displacement of the abomasum ${ }^{1}$

\begin{tabular}{|c|c|c|c|c|c|c|}
\hline \multirow[b]{2}{*}{$\mathrm{PC}$} & \multirow{2}{*}{$\begin{array}{c}\text { Proportion }{ }^{2} \\
(\%)\end{array}$} & \multicolumn{3}{|c|}{ Compartment } & \multirow[b]{2}{*}{ SEM } & \multirow[b]{2}{*}{$P$-value } \\
\hline & & Abdominal & NEFA & Subcutaneous & & \\
\hline PC1 & 51.6 & $-1.86^{\mathrm{a}}$ & $-2.03^{\mathrm{a}}$ & $2.91^{\mathrm{b}}$ & 0.296 & $<0.0001$ \\
\hline $\mathrm{PC} 2$ & 21.1 & $-1.37^{\mathrm{a}}$ & $2.16^{\mathrm{b}}$ & $-0.19^{\mathrm{c}}$ & 0.180 & $<0.0001$ \\
\hline
\end{tabular}

${ }^{\mathrm{a}-\mathrm{c}}$ Values with different subscripts in the same row significantly differ $(P<0.05)$.

${ }^{1}$ Values are model least squares means.

${ }^{2}$ Proportion of variance explained by the PC.

lipogenic rate in abdominal fat. In nonlactating heifers, a larger adipocyte size was found in abdominal fat compared with subcutaneous fat (Eguinoa et al., 2003), which was recently confirmed for retroperitoneal but not omental fat in lactating dairy cows (Akter et al., 2011). The latter authors concluded that retroperitoneal fat was preferentially mobilized during peak lactation and as DIM increase, the tissue becomes more sensitive. Recently, Nikkhah et al. (2008) reported that the internal fat mass in dairy cows during the dry period increased over $70 \%$ without a concomitant increase in BCS, when cows were moderately overfed during an 8-wk period. This also suggests increased ABD FA metabolism during an anabolic period. Interestingly, in our study in which cows were presented for a correction of LDA, we observed animals with a moderately low BCS but with a concomitant high OFS (indicated by the diagram in Figure 1). The latter seems in contrast to the higher catabolic activity of $\mathrm{ABD}$ and provides interesting evidence to question the change in BCS as an accurate estimator of the lipolysis rate in early lactating dairy cows.

\section{CONCLUSIONS}

The current study provides evidence for a different FA profile in ABD versus SUBC fat stores in dairy cows suffering from LDA. The results of the multivariate approach, which included the desaturase indices along with the entire FA profile of ABD, SUBC, and NEFA, support the hypothesis of preferential mobilization of $\mathrm{ABD}$ in dairy cows suffering from LDA.

\section{ACKNOWLEDGMENTS}

The authors thank C. Melis (Laboratory for Animal Nutrition and Animal Product Quality, Melle, Belgium) for her excellent technical support and all veterinarians for participating in the trial. Bruno Vlaeminck is a postdoctoral fellow of the Fund for Scientific ResearchFlanders (Belgium). This research was funded by the
Institute for the Promotion of Innovation by Science and Technology in Flanders (grant no. 050683).

\section{REFERENCES}

Aardema, H., P. L. A. M. Vos, F. Lolicato, B. A. J. Roelen, H. M. Knijn, A. B. Vaandrager, J. B. Helms, and B. M. Gadella. 2011. Oleic acid prevents detrimental effects of saturated fatty acids on bovine oocyte developmental competence. Biol. Reprod. 85:62-69.

Akter, S. H., S. Haussler, S. Danicke, U. Muller, D. von Soosten, J. Rehage, and H. Sauerwein. 2011. Physiological and conjugated linoleic acid-induced changes of adipocyte size in different fat depots of dairy cows during early lactation. J. Dairy Sci. 94:2871-2882.

Arner, P. 1998. Not all fat is alike. Lancet 351:1301-1302.

Baldwin, R. L. VI, K. R. McLeod, J. P. McNamara, T. H. Elsasser, and R. G. Baumann. 2007. Influence of abomasal carbohydrates on subcutaneous, omental, and mesenteric adipose lipogenic and lipolytic rates in growing beef steers. J. Anim. Sci. 85:2271-2282.

Barnes, R. J., R. S. Comline, and A. Dobson. 1983. Changes in the blood-flow to the digestive organs of sheep induced by feeding. Q. J. Exp. Physiol. 68:77-88.

Bauman, D. E., and W. B. Currie. 1980. Partitioning of nutrients during pregnancy and lactation-A review of mechanisms involving homeostasis and homeorhesis. J. Dairy Sci. 63:1514-1529.

Beaulieu, A. D., J. K. Drackley, and N. R. Merchen. 2002. Concentrations of conjugated linoleic acid (cis-9, trans-11-octadecadienoic acid) are not increased in tissue lipids of cattle fed a highconcentrate diet supplemented with soybean oil. J. Anim. Sci. 80:847-861.

Bobe, G., J. W. Young, and D. C. Beitz. 2004. Invited review: Pathology, etiology, prevention, and treatment of fatty liver in dairy cows. J. Dairy Sci. 87:3105-3124.

Calder, P. C. 2009. Polyunsaturated fatty acids and inflammatory processes: New twists in an old tale. Biochimie 91:791-795.

Chang, J. H. P., D. K. Lunt, and S. B. Smith. 1992. Fatty-acid composition and fatty-acid elongase and stearoyl-CoA desaturase activities in tissues of steers fed high oleate sunflower seed. J. Nutr. 122:2074-2080.

Chapinal, N., M. Carson, T. F. Duffield, M. Capel, S. Godden, M. Overton, J. E. P. Santos, and S. J. LeBlanc. 2011. The association of serum metabolites with clinical disease during the transition period. J. Dairy Sci. 94:4897-4903.

Contreras, G. A., N. J. O'Boyle, T. H. Herdt, and L. M. Sordillo. 2010. Lipomobilization in periparturient dairy cows influences the composition of plasma nonesterified fatty acids and leukocyte phospholipid fatty acids. J. Dairy Sci. 93:2508-2516.

Contreras, G. A., and L. M. Sordillo. 2011. Lipid mobilization and inflammatory responses during the transition period of dairy cows. Comp. Immunol. Microbiol. Infect. Dis. 34:281-289.

De Smet, S., K. Raes, and D. Demeyer. 2004. Meat fatty acid composition as affected by fatness and genetic factors: A review. Anim Res 53:81-98. 
Desnoyers, M., S. Giger-Reverdin, D. Sauvant, and C. Duvaux-Ponter. 2011. The use of a multivariate analysis to study between-goat variability in feeding behavior and associated rumen $\mathrm{pH}$ patterns. J. Dairy Sci. 94:842-852.

Douglas, G. N., J. Rehage, A. D. Beaulieu, A. O. Bahaa, and J. K. Drackley. 2007. Prepartum nutrition alters fatty acid composition in plasma, adipose tissue, and liver lipids of periparturient dairy cows. J. Dairy Sci. 90:2941-2959.

Drackley, J. K., T. R. Overton, and G. N. Douglas. 2001. Adaptations of glucose and long-chain fatty acid metabolism in liver of dairy cows during the periparturient period. J. Dairy Sci. 84(E. Suppl.):E100-E112.

Edmonson, A. J., I. J. Lean, L. D. Weaver, T. Farver, and G. Webster. 1989. A body condition scoring chart for Holstein dairy cows. J. Dairy Sci. 72:68-78.

Eguinoa, P., S. Brocklehurst, A. Arana, J. A. Mendizabal, R. G. Vernon, and A. Purroy. 2003. Lipogenic enzyme activities in different adipose depots of Pirenaican and Holstein bulls and heifers taking into account adipocyte size. J. Anim. Sci. 81:432-440.

Eichhorn, J. M., L. J. Coleman, E. J. Wakayama, G. J. Blomquist, C. M. Bailey, and T. G. Jenkins. 1986. Effects of breed type and restricted versus ad-libitum feeding on fatty-acid composition and cholesterol content of muscle and adipose tissue from mature bovine females. J. Anim. Sci. 63:781-794.

Emery, R. S., J. S. Liesman, and T. H. Herdt. 1992. Metabolism of long-chain fatty acids by ruminant liver. J. Nutr. 122:832-837.

Etherton, T. D., D. E. Bauman, and J. R. Romans. 1977. Lipolysis in subcutaneous and perirenal adipose-tissue from sheep and dairy steers. J. Anim. Sci. 44:1100-1106.

Fievez, V., B. Vlaeminck, M. S. Dhanoa, and R. J. Dewhurst. 2003 Use of principal component analysis to investigate the origin of heptadecenoic and conjugated linoleic acids in milk. J. Dairy Sci. 86:4047-4053.

Gregory, N. G., R. J. Christopherson, and D. Lister. 1986. Adiposetissue capillary blood-flow in relation to fatness in sheep. Res. Vet. Sci. 40:352-356.

Hajer, G. R., T. W. van Haeften, and F. L. J. Visseren. 2008. Adipose tissue dysfunction in obesity, diabetes, and vascular diseases. Eur. Heart J. 29:2959-2971.

Håversen, L., K. N. Danielsson, L. Fogelstrand, and O. Wiklund. 2009. Induction of proinflammatory cytokines by long-chain saturated fatty acids in human macrophages. Atherosclerosis 202:382-393.

Herdt, T. H. 2000. Ruminant adaptation to negative energy balance: Influences on the etiology of ketosis and fatty liver. Vet. Clin. North Am. Food Anim. Pract. 16:215-230.

Jensen, M. D. 2007. Adipose tissue metabolism-An aspect we should not neglect? Horm. Metab. Res. 39:722-725.

Jorritsma, R., M. W. de Groot, P. L. Vos, T. A. Kruip, T. Wensing, and J. P. Noordhuizen. 2003. Acute fasting in heifers as a model for assessing the relationship between plasma and follicular fluid NEFA concentrations. Theriogenology 60:151-161.

LeBlanc, S. J., K. E. Leslie, and T. F. Duffield. 2005. Metabolic predictors of displaced abomasum in dairy cattle. J. Dairy Sci. 88:159-170.

Leroy, J. L., P. Bossaert, G. Opsomer, and P. E. Bols. 2011. The effect of animal handling procedures on the blood non-esterified fatty acid and glucose concentrations of lactating dairy cows. Vet. J. $187: 81-84$.

Leroy, J. L. M. R., T. Vanholder, B. Mateusen, A. Christophe, G. Opsomer, A. de Kruif, G. Genicot, and A. Van Soom. 2005. Nonesterified fatty acids in follicular fluid of dairy cows and their effect on developmental capacity of bovine oocytes in vitro. Reproduction 130:485-495.

Lourenço, M., S. De Smet, V. Fievez, and K. Raes. 2007. Effect of botanical composition of silages on rumen fatty acid metabolism and fatty acid composition in longissimus muscle and subcutaneous fat of lambs. Animal 1:911-921.

Mattos, R., C. R. Staples, and W. W. Thatcher. 2000. Effects of dietary fatty acids on reproduction in ruminants. Rev. Reprod. $5: 38-45$.
Moallem, U., Y. Folman, A. Bor, A. Arav, and D. Sklan. 1999. Effect of calcium soaps of fatty acids and administration of somatotropin on milk production, preovulatory follicular development, and plasma and follicular fluid lipid composition in high yielding dairy cows. J. Dairy Sci. 82:2358-2368.

Mora, S., and J. E. Pessin. 2002. An adipocentric view of signaling and intracellular trafficking. Diabetes Metab. Res. Rev. 18:345-356.

Mukesh, M., M. Bionaz, D. E. Graugnard, J. K. Drackley, and J. J. Loor. 2010. Adipose tissue depots of Holstein cows are immune responsive: Inflammatory gene expression in vitro. Domest. Anim. Endocrinol. 38:168-178.

Nakamura, M. T., and T. Y. Nara. 2004. Structure, function, and dietary regulation of delta 6 , delta 5 , and delta 9 desaturases. Annu. Rev. Nutr. 24:345-376.

Nikkhah, A., J. J. Loor, R. L. Wallace, D. Graugnard, J. Vasquez, B. Richards, and J. K. Drackley. 2008. Moderate excesses of dietary energy markedly increase visceral adipose tissue mass in non-lactating dairy cows. J. Dairy Sci. 91(E-Suppl. 1):ii. (Abstr.)

Oka, A., F. Iwaki, T. Dohgo, S. Ohtagaki, M. Noda, T. Shiozaki, O. Endoh, and M. Ozaki. 2002. Genetic effects on fatty acid composition of carcass fat of Japanese Black Wagyu steers. J. Anim. Sci. 80:1005-1011

Raes, K., S. de Smet, and D. Demeyer. 2001. Effect of double-muscling in Belgian Blue young bulls on the intramuscular fatty acid composition with emphasis on conjugated linoleic acid and polyunsaturated fatty acids. Anim. Sci. 73:253-260.

Rukkwamsuk, T., M. J. H. Geelen, T. A. M. Kruip, and T. Wensing. 2000. Interrelation of fatty acid composition in adipose tissue, serum, and liver of dairy cows during the development of fatty liver postpartum. J. Dairy Sci. 83:52-59.

Sato, H., and A. Inoue. 2006. Decrease in stearic acid proportions in adipose tissues and liver lipids in fatty liver of dairy cows. Anim. Sci. J. 77:347-351.

Siebert, B. D., W. S. Pitchford, Z. A. Kruk, H. Kuchel, M. P. B. Deland, and C. D. K. Bottema. 2003. Differences in delta9 desaturase activity between Jersey- and Limousin-sired cattle. Lipids 38:539-543.

St. John, L. C., D. K. Lunt, and S. B. Smith. 1991. Fatty-acid elongation and desaturation enzyme-activities of bovine liver and subcutaneous adipose-tissue microsomes. J. Anim. Sci. 69:1064-1073.

Turner, A. S., C. W. McIlwraith, and B. L. Hull. 1989. Techniques in Large Animal Surgery. 2nd ed. Lea \& Febiger, Philadelphia, PA.

Van Eetvelde, M., S. De Smet, and G. Opsomer. 2011. Het inschatten van energiereserves onder de vorm van vet bij hoogproductieve melkkoeien. Flem. Vet. J. 80:31-37.

Van Hoeck, V., R. G. Sturmey, P. Bermejo-Alvarez, D. Rizos, A. Gutierrez-Adan, H. J. Leese, P. E. J. Bols, and J. L. M. R. Leroy. 2011. Elevated non-esterified fatty acid concentrations during bovine oocyte maturation compromise early embryo physiology. PLoS One 6:e23183.

Vanholder, T., J. L. M. R. Leroy, A. Van Soom, G. Opsomer, D. Maes, M. Coryn, and A. de Kruif. 2005. Effect of non-esterified fatty acids on bovine granulosa cell steroidogenesis and proliferation in vitro. Anim. Reprod. Sci. 87:33-44.

Vernon, R. G. 1980. Lipid metabolism in the adipose tissue of ruminant animals. Prog. Lipid Res. 19:23-106.

Wajchenberg, B. L. 2000. Subcutaneous and visceral adipose tissue: Their relation to the metabolic syndrome. Endocr. Rev. 21:697738

Zachut, M., A. Arieli, H. Lehrer, L. Livshitz, S. Yakoby, and U. Moallem. 2010a. Effects of increased supplementation of n-3 fatty acids to transition dairy cows on performance and fatty acid profile in plasma, adipose tissue, and milk fat. J. Dairy Sci. 93:5877-5889.

Zachut, M., I. Dekel, H. Lehrer, A. Arieli, A. Arav, L. Livshitz, S. Yakoby, and U. Moallem. 2010b. Effects of dietary fats differing in n-6:n-3 ratio fed to high-yielding dairy cows on fatty acid composition of ovarian compartments, follicular status, and oocyte quality. J. Dairy Sci. 93:529-545. 